\title{
Dimensional consistency achieved in high-performance synchronizing $\operatorname{hubs}^{\left({ }^{\circ}\right.}$
}

\author{
P. García*, M. Campos** and J. M. Torralba** and ***
}

\begin{abstract}
The tolerances of parts produced for the automotive industry are so tight that any small process variation may mean that the product does not fulfill them. As dimensional tolerances decrease, the material properties of parts are expected to be improved. Depending on the dimensional and material requirements of a part, different production routes are available to find robust processes, minimizing cost and maximizing process capability. Dimensional tolerances have been reduced in recent years, and as a result, the double pressing-double sintering production via ("2P2S") has again become an accurate way to meet these increasingly narrow tolerances. In this paper, it is shown that the process parameters of the first sintering have great influence on the following production steps and the dimensions of the final parts. The roles of factors other than density and the second sintering process in defining the final dimensions of product are probed. All trials were done in a production line that produces synchronizer hubs for manual transmissions, allowing the maintenance of stable conditions and control of those parameters that are relevant for the product and process.
\end{abstract}

Keywords Double pressing and sintering; Dimensional control; High performance parts.

\section{Consistencia dimensional en cubos de sincronización de alto rendimiento}

Resumen

Palabras Clave

\begin{abstract}
Las tolerancias en componentes fabricados para la industria del automóvil son tan estrechas que cualquier modificación en las variables del proceso puede provocar que no se cumplan. Una disminución de las tolerancias dimensionales, puede significar una mejora en las propiedades de las piezas. Dependiendo de los requerimientos dimensionales y del material, distintas rutas de procesado pueden seguirse para encontrar un método de procesado robusto, que minimice costes y maximice la capacidad del proceso. En los últimos años, la tolerancia dimensional se ha ajustado gracias a métodos de procesado como el doble prensado/doble sinterizado ("2P2S"), método de gran precisión para conseguir estrechas tolerancias. En este trabajo, se muestra que los parámetros de procesado del primer ciclo de sinterización tienen una gran importancia en los pasos siguientes y en las dimensiones finales alcanzadas. Todos los ciclos se han realizado en una línea real de fabricación de cubos sincronizadores para cambio manual, asegurando el mantenimiento de condiciones estables y control de proceso relevante para el producto y el proceso en sí mismo.
\end{abstract}

Doble prensado y sinterizado; Control dimensional; Componentes de altas prestaciones.

\section{INTRODUCTION}

The properties and performance of low-alloyed sintered steels depend on their composition and processing conditions. The main application of this family of steels is the automotive industry, which requires production sets with a high performance-to-price relationship. The production of highly reliable sintered parts, based on materials that can ensure high performance, dimensional stability together with reasonable cost is one of the main aims of the PM industry ${ }^{[1-3]}$. Improvements in this field can be achieved in two different ways: by designing high alloying systems or new alloying systems, or by improving the density through the processing route. It is important to identify the step of the processing route that can produce improved density (the pressing, the sintering, or even post-sintering

(•) Trabajo recibido el día 7 de diciembre de 2011 y aceptado en su forma final el día 4 de octubre de 2012 .

* Quality Manager PMG Asturias Powder Metal S.A.U.

** Materials Science and Engineering Department, Universidad Carlos III de Madrid.

*** IMDEA Materials Institute, de Madrid. 
operations). For structural parts, pressing is responsible for the densification from an apparent density near $3.0 \mathrm{~g} / \mathrm{cm}^{3}$ to $6.9-7.0 \mathrm{~g} / \mathrm{cm}^{3}$ or even higher, but sintering can be considered to be the most important step in the final densification process since if it is not done properly, mechanical properties of final product will be not the accurate ones, whatever green density is. Today, the combination of a good pressing process with a well-performed sintering cycle makes it possible to produce a new generation of high-performance sintered steels with well-controlled porosity, a good microstructural balance and, as a consequence, high performance $^{[4 \text { and 5]. }}$.

Nevertheless, an improved density does not ensure that the product will reach the design objectives for which it was intended. One of the most important aims of PM low-alloyed steel components developed for the automotive industry is the achievement of close dimensional tolerances after the sintering step. The alloying content and its scatter, sintering time, density variation after pressing, and sintering temperature are all directly related to the conformation of a part to its tolerance ${ }^{[6]}$. The quenching conditions are important not only because they determine material properties, but also because they define the dimensional behavior of sinterhardened parts.

In the case of synchronizer hubs, there are several kinds of dimensional tolerance. Diameters that are not involved directly in the function of the part may have tolerances of approximately $0.1 \mathrm{~mm}$, but this value can be reduced to $20 \mu \mathrm{m}$ in the case of functional diameters. At the same time, one of the most important dimensional parameters is the quality of splines, both internal and external. The normal value for external teeth is $\mathrm{Q} 9$, but $\mathrm{Q} 8$ can be required. This requirement means not only that the diameters must fulfill the tolerance, but also errors in the teeth should be controlled. According ISO 5480-1, errors in the teeth for the parts considered in this paper are: $\mathrm{f}_{\mathrm{p}}=17 \mu \mathrm{m}, \mathrm{F}_{\mathrm{p}}=40 \mu \mathrm{m}, \mathrm{F}_{\alpha}=21 \mu \mathrm{m}$ and $\mathrm{F}_{\beta}=14 \mu \mathrm{m}$.

Additionally, this kind of parts use to present density gradients which produce that dimensional variations are not uniform, so at this point, materials that have minimal swelling or shrinkage during sintering and low deformation during quenching (in case of sinter-hardening processes) are necessary to achieve described requirements. It is also necessary to define the process parameters that allow the development of a robust process with excellent capability. In this case, a double pressing and sintering process ("2P2S") is an attractive possibility.

In the 1980s, complex Fe-Cu-Ni-Mo-C systems were developed based on the mixing of powders ${ }^{[7-10]}$, and these systems were later produced with the diffusion bonding alloying method ${ }^{[11-16]}$. These alloying systems were partially replaced in the 1990s by an alloying system that introduced chromium, and much later, manganese was introduced. The systems based on $\mathrm{Ni}-\mathrm{Cu}-\mathrm{Mo}$ are the most widely used in the industry today because of their high reliability with respect to dimensional stability and mechanical properties, and they have been used in 2P2S production processes for years. Most scientific investigations use these materials as standard specimens, but little information and few results are obtained from real parts produced in real industrial conditions from these materials ${ }^{[17]}$.

The main objective of this paper is to obtain information regarding the influence of pre-sintering conditions on the dimensional and material properties of components (synchronizing hub, in figure 1) that are assembled in gearboxes for manual transmissions.

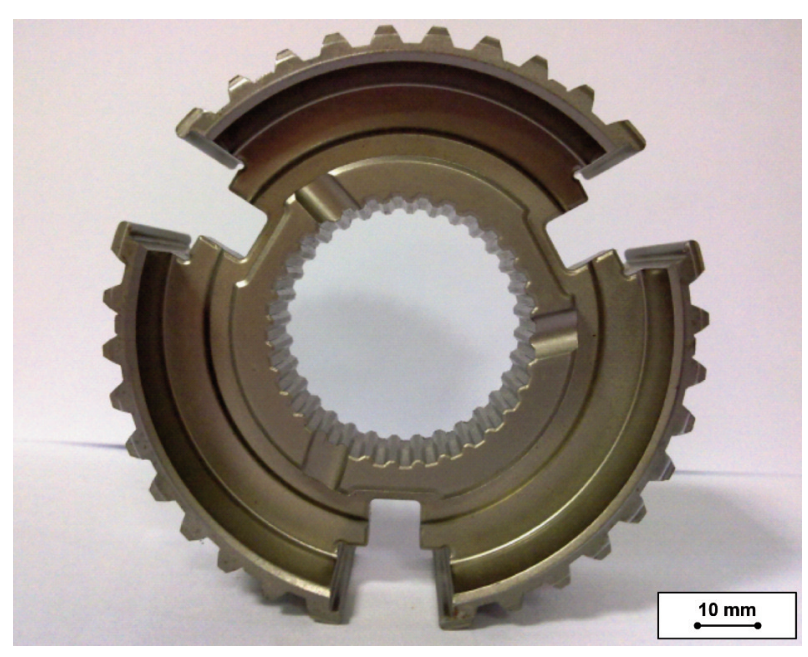

Figure 1. Synchronizing hub used in this work.

Figura 1. Cubo sincronizador utilizado en este trabajo.

From a dimensional perspective, the pre-sintering time and temperature have been tested for the comparison of product dimensions. Regarding the material properties, the hardness, density and the results of an 'in house' breaking load test have been analyzed. All other process parameters, including tooling, have been kept constant to evaluate only the influence of the pre-sintering conditions.

In this work, two of the most-used steel compositions for structural parts (Distaloy AE and HP1 grades, from Höganäs AB, Sweden) have been selected for use in the study, but a double pressing double sintering process (2P2S) was used to ensure high performance. All components were manufactured in a large-scale production route, following the production line. All process step parameters were 
controlled to avoid damage to the production equipment, including both tooling and machines.

\section{EXPERIMENTAL PROCEDURE}

The materials used in this work are those described in table I.
These two compositions are reliable from the point of view of dimensional contro[ ${ }^{[18}$ and 19$]$. Ni4Cu2Mo1.5 can be considered to be a "high strength material" and $\mathrm{Ni} 4 \mathrm{Cu} 1.5 \mathrm{Mo0} .5$ can be considered a "medium strength material". Both materials follow a double press and sintering process. First materials are pressed and pre-sintered (state 1P1S) in the conditions of tables II and III.

Table I. Chemical composition of base irons (wt \%)

Tabla I. Composición química de los polvos de hierro base (\% en peso)

\begin{tabular}{lllllll}
\hline Nomenclature & Material & $\mathrm{Ni}^{\mathrm{D}}$ & $\mathrm{Cu}^{\mathrm{D}}$ & Mo & $\mathbf{C}$ & Wax \\
\hline Ni4Cu2Mo1.5 & Distaloy HP1 & 4 & 2 & $1.4^{\mathrm{P}}$ & 0.5 & 0.8 \\
Ni4Cu1.5Mo0.5 & Distaloy AE & 4 & 1.5 & $0.5^{\mathrm{D}}$ & 0.6 & 0.8
\end{tabular}

$\mathrm{D}=$ Diffusion alloyed, $\mathrm{P}=$ Pre-alloyed

Table II. Density and compacting pressure first pressing

Tabla II. Densidad y presión de compactación después del primer prensado

\begin{tabular}{|c|c|c|c|c|c|}
\hline \multirow{2}{*}{\multicolumn{2}{|c|}{$\begin{array}{c}\text { Compacting } \\
\text { pressure } \\
\text { (MPa) }\end{array}$}} & \multicolumn{4}{|c|}{ Density $\left(\mathrm{g} / \mathrm{cm}^{3}\right)$} \\
\hline & & $\begin{array}{l}\text { Upper } \\
\text { external } \\
\text { spline } \\
\text { area }\end{array}$ & $\begin{array}{l}\text { Lower } \\
\text { external } \\
\text { spline } \\
\text { area }\end{array}$ & $\begin{array}{c}\text { Middle } \\
\text { area }\end{array}$ & $\begin{array}{c}\text { Internal } \\
\text { spline } \\
\text { area }\end{array}$ \\
\hline Ni4Cu2Mo1.5 & 575 & 6.95 & 6.98 & 6.94 & 6.94 \\
\hline Ni4Cu1.5Mo0.5 & 435 & 6.95 & 6.93 & 6.95 & 6.95 \\
\hline
\end{tabular}

Table III. Sintering conditions

Tabla III. Condiciones de sinterización

\begin{tabular}{|c|c|c|c|c|c|}
\hline & \multicolumn{2}{|c|}{$\begin{array}{l}\mathrm{N}_{2}-\mathrm{H}_{2} \text { atmosphere } \\
\left(90 \% \mathrm{~N}_{2} 10 \% \mathrm{H}_{2}\right)\end{array}$} & \multicolumn{3}{|c|}{$\begin{array}{l}\text { Endo gas atmosphere } \\
\text { (25\% } \mathrm{CH}_{4}-75 \% \text { Air) }\end{array}$} \\
\hline & $\begin{array}{l}\text { Pre-sintering } \\
\mathrm{T}\left({ }^{\circ} \mathrm{C}\right)\end{array}$ & $\begin{array}{l}\text { Presintering time } \\
\qquad \mathrm{t}=45 \mathrm{~min}\end{array}$ & $\begin{array}{l}\text { Sintering } \\
\mathrm{T}\left({ }^{\circ} \mathrm{C}\right)\end{array}$ & $\begin{array}{l}\text { Sintering } \\
\text { time (min) }\end{array}$ & $\begin{array}{l}\text { Cooling } \\
\text { rate }\left({ }^{\circ} \mathrm{C} / \mathrm{s}\right)\end{array}$ \\
\hline \multirow{2}{*}{ Ni4Cu2Mo1.5 } & 825 & $\underset{2 t}{t}$ & \multirow{5}{*}{1135} & \multirow{5}{*}{25} & \multirow{5}{*}{$1-1.5$} \\
\hline & 880 & $\mathrm{t}$ & & & \\
\hline \multirow{3}{*}{ Ni4Cu1.5Mo0.5 } & 825 & $\mathrm{t}$ & & & \\
\hline & $0<0$ & $2 \mathrm{t}$ & & & \\
\hline & 880 & $\mathrm{t}$ & & & \\
\hline
\end{tabular}


Table IV. Density after second pressing

Tabla IV. Densidad después del segundo prensado

\begin{tabular}{lcccc}
\hline & \multicolumn{4}{c}{ Density $\left(\mathbf{g} / \mathbf{c m}^{3}\right)$} \\
\cline { 2 - 5 } & $\begin{array}{c}\text { Upper } \\
\text { external } \\
\text { spline area }\end{array}$ & $\begin{array}{c}\text { Lower } \\
\text { external } \\
\text { spline area }\end{array}$ & $\begin{array}{c}\text { Middle } \\
\text { area }\end{array}$ & $\begin{array}{c}\text { Internal } \\
\text { spline } \\
\text { area }\end{array}$ \\
\hline Ni4Cu2Mo1.5 & 7.01 & 7.02 & 7.05 & 7.03 \\
Ni4Cu1.5Mo0.5 & 7.10 & 7.08 & 7.10 & 7.15 \\
\hline
\end{tabular}

After materials are presintered, are pressed again (Fig. 4) to get the densities described in table IV (final state 2P2S).

The dimensions in both the first and second press steps were fixed to obtain a proper value of the dimension $\mathrm{H}$ (Fig. 1). From a functional perspective, this characteristic is one of the most important, and depending on tolerances, even it can define the production process $(1 \mathrm{P} 1 \mathrm{~S}$ or $2 \mathrm{P} 2 \mathrm{~S}$, machining before or after sintering, sizing, etc.). The density and the $\mathrm{H}$ dimension must be balanced in the full part, but in those areas with functional applications, this relation is even more critical to the accurate behavior of the part in the gearbox.

During the experimental procedure, the $\mathrm{H}$ parameter, and consequently the density, were kept constant for each material in the pressing steps. As a result, it is possible to measure the influence of the pre-sintering conditions on the other process parameters and on the part dimensions.

After the first pressing step, the density is controlled in different areas to ensure that the filling and pressing have been done correctly and that the values are homogeneous in the full part (in figure 2 are explained the three different areas considered for measuring the density).

Table II shows the values of the density in different areas for both materials, obtained by the Archimedes method. The compacting pressure for each material is also shown. Experimental trials were carried out as shown in table III.

Depending on the pre-sintering conditions, time and temperature, it was found that the compacting pressure parameter of the second pressing varies. As in the case of the first pressing step, the value of the $\mathrm{H}$ parameter was taken as the basis to adjust the compacting pressure. This value was kept constant for each material in all three trials, which means that the density of this area was kept constant as well. The density after the second pressing step is shown in table IV. The compacting pressure of the second pressing is shown as one of the results of this trial.

After the first cycle of pressing and sintering and once the full processing cycle (2P2S) was done, the dimensional variation of the hubs was evaluated by measuring the external and internal diameters. The apparent Brinell hardness (HB) has also been measured in both process stages.

To evaluate the strength of the hubs, an 'inhouse' testing procedure was developed. In figure 3,
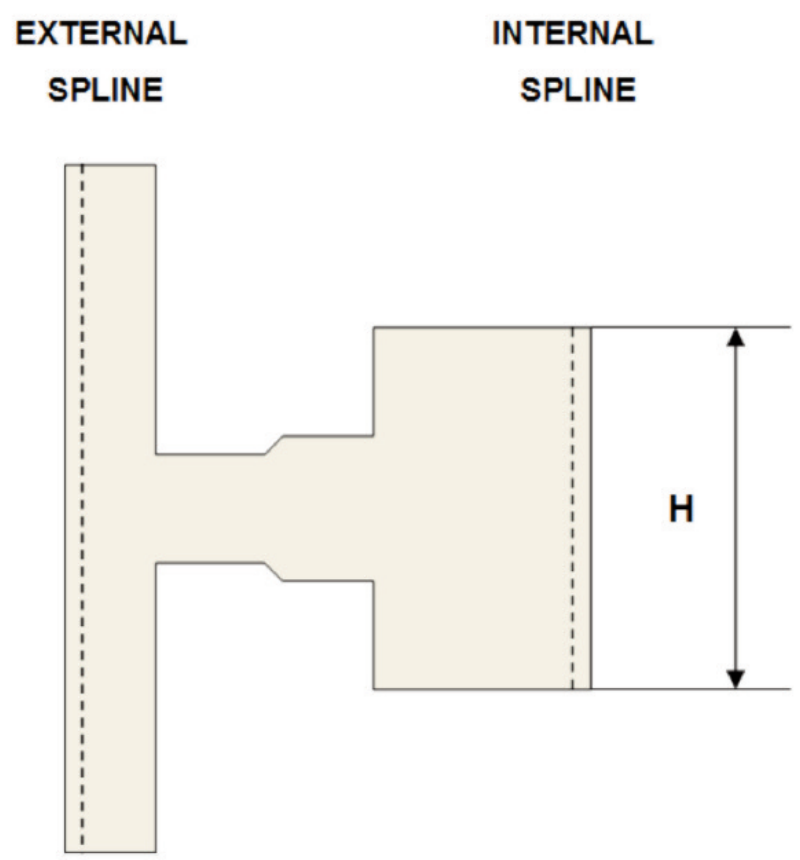

Figure 2. Sketch of component cross-section. Measuring areas for density.

Figura 2. Áreas seleccionadas para la medida de densidad. 
the basis of the method is described. The component is loaded by an expansive clamp, which is located in an internal spline, until the part breaks. The load is applied through a cone, and in all the cases at the same speed, allowing a direct comparison of the breaking load and the maximum displacement before breaking between all the parts.

Finally, some metallographic analyses were done to determine the evolution of the material through the processing route.

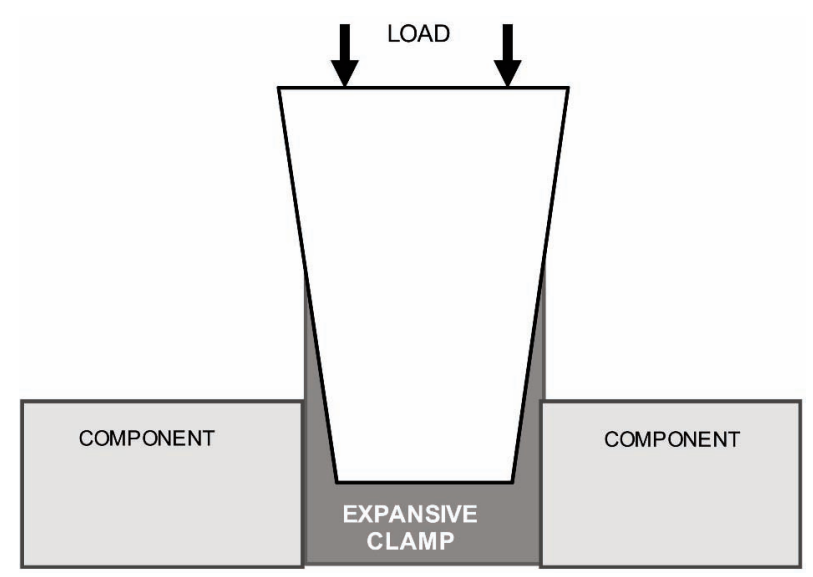

Figure 3. Sketch of the mechanical testing procedure.

Figura 3. Esquema del método de ensayo mecánico.

\section{RESULTS AND DISCUSSION}

\subsection{Second pressing compacting pressure and dimensional results}

Figure 4 shows the compacting pressure in the second pressing, for each pre-sintering condition, on both materials, taking the second pressing after $825^{\circ} \mathrm{C}-\mathrm{t}$ as a reference.

Figures 5 and 6 show the total dimensional results for both materials in all trials, after the first pressingsintering cycle, and after the second one. Because the behavior of the internal and external diameters is similar, only the external diameters are shown in the figures.

The dimensions after pre-sintering at $825^{\circ} \mathrm{C}$-t are taken as a reference, and all other measurements are specified in reference to this value for each material. It is important to note that because tolerances are so tight, a percentage variation of just $0.02 \%$ is highly significant and may mean the production of parts is within or out of tolerance.

Figure 5 shows the dimensional results for $\mathrm{Ni4Cu}$ Mo1.5. When the pre-sintering temperature is $880^{\circ} \mathrm{C}$, significant swelling is produced at this stage. This fact must be taken into account in the tooling design to avoid further damages. The part then shrinks after sintering. When the pre-sintering time is doubled, the size of the resulting parts is smaller. Nevertheless, the dimensions of the parts pre-sintered at $825^{\circ} \mathrm{C}$ have similar dimensional behavior after sintering. When the dimensions after pre-sintering at $825^{\circ} \mathrm{C}$-t are taken as a reference, in both cases after sintering, the parts present swelling. This result is opposite to that obtained when the pre-sintering temperature is $880^{\circ} \mathrm{C}$ : swelling after the first sintering is followed by shrinkage in the final sintering. This observation supports the claim that for this material, the pre-sintering temperature defines the dimensions of the final part.

Figure 6 shows the results for $\mathrm{Ni} 4 \mathrm{Cu} 1.5 \mathrm{Mo} 0.5$. In this case, the dimensional behavior of the parts is similar in all trials. Minor shrinkage is observed when the first-sinter temperature is increased to $880^{\circ} \mathrm{C}$, and also when the time is doubled. In all cases, swelling exists after the second sintering. Significant dimensional differences cannot be found for this material, regardless of the pre-sintering conditions.

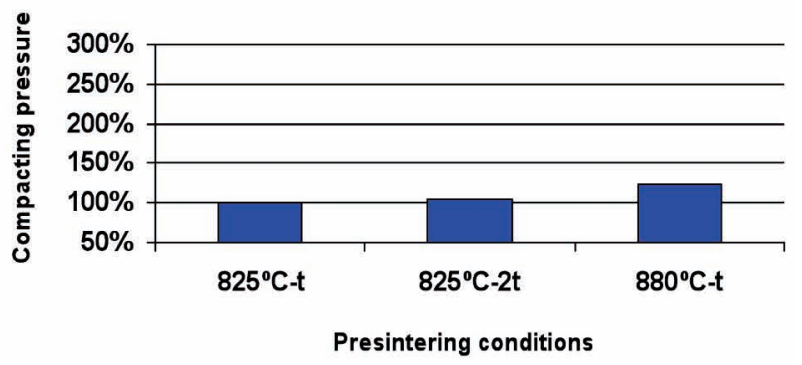

Figure 4. Compacting pressure during the second pressing on both materials, left Ni4Cu2Mo1.5, right Ni4Cu1.5Mo0.5.

Figura 4. Presión de compactación durante el segundo prensado de los dos materiales, izquierda Ni4Cu2Mo1,5, derecha Ni4Cu1,5Mo0,5. 


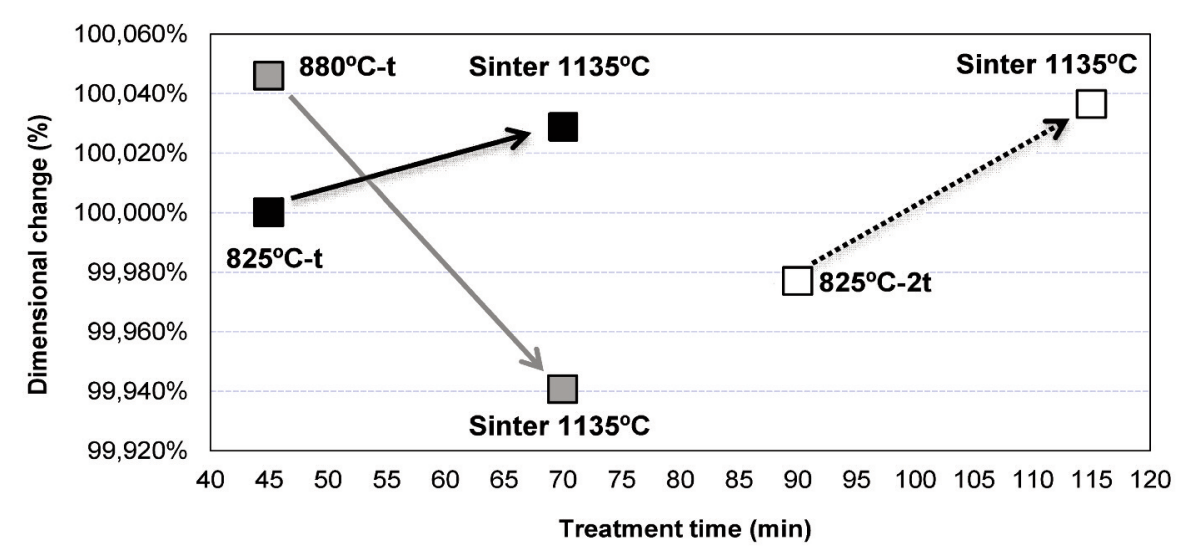

Figure 5. Ni4Cu2Mo1.5, dimensional variation per trial.

Figura 5. Ni4Cu2Mo1,5, variación dimensional por ciclo.

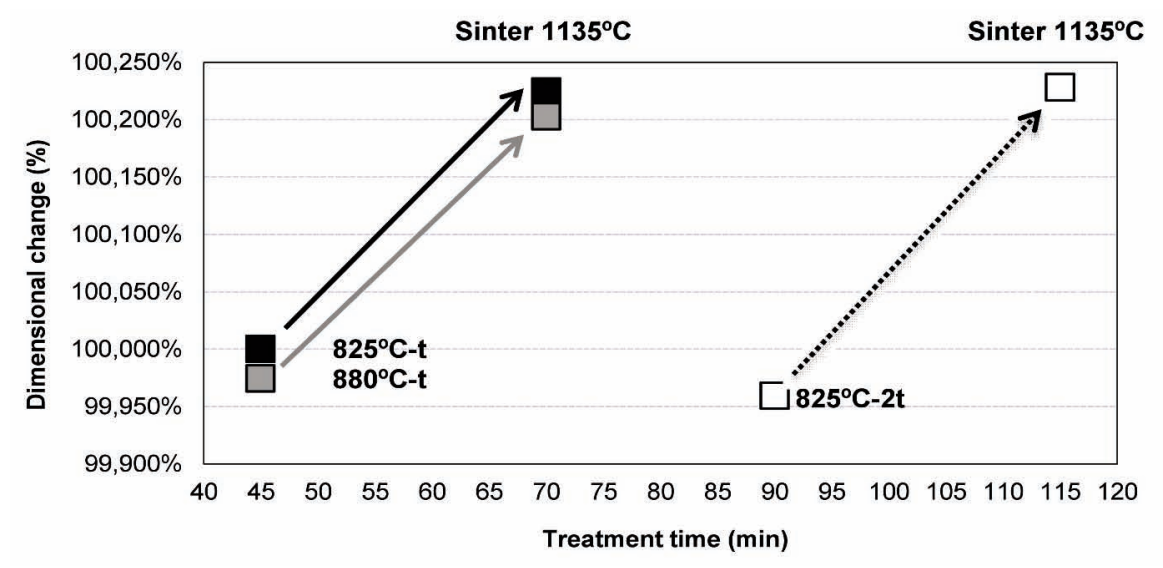

Figure 6. Ni4Cu1.5Mo0.5, dimensional variation per trial.

Figura 6. Ni4Cu1,5Mo0,5, variación dimensional por ciclo.

For this material and within the parameters of this study, the pre-sintering time and temperature have no decisive influence on the dimensions of the final part.

Nevertheless, both materials show good process stability in terms of variation; the observed shrinkage for $\mathrm{Ni4Cu} 2 \mathrm{Mo} 1.5$ should be taken into account in the tooling design, allowing the final part to fulfill the drawing specifications. These materials show good dimensional behavior because of an ideal combination of copper and nickel that balances the growth effect of the copper with the shrinkage produced by the presence of nickel.

\subsection{Hardness results}

In figure 7, the values obtained for the hardness after the full 2P2S cycles are displayed. As could be expected, the benefit of the alloying elements of $\mathrm{Ni4Cu} 2 \mathrm{Mo} 1.5$ is the resulting increase of the hardness.

The hardness is also affected by the higher hardenability of Ni4Cu2Mo1.5, which has more martensite in its microstructure and, as a consequence, possesses increased hardness. The variability of the hardness values is much higher for materials that are pre-sintered at a higher temperature. The values obtained for the dimensional changes and hardness are in full agreement with those obtained using the standard test samples ${ }^{[20]}$.

Significantly, the hardness values in the final parts are not very different from the ones obtained when the pre-sintering conditions were $825^{\circ} \mathrm{C}$-t. For $\mathrm{Ni4Cu} 2 \mathrm{Mo} 1.5$, the hardness values in final part (after $2 \mathrm{P} 2 \mathrm{~S}$ process) for a pre-sintering temperature of $880^{\circ} \mathrm{C}$ are slightly higher, but not sufficient to ensure that the material property (hardness) has been increased. 


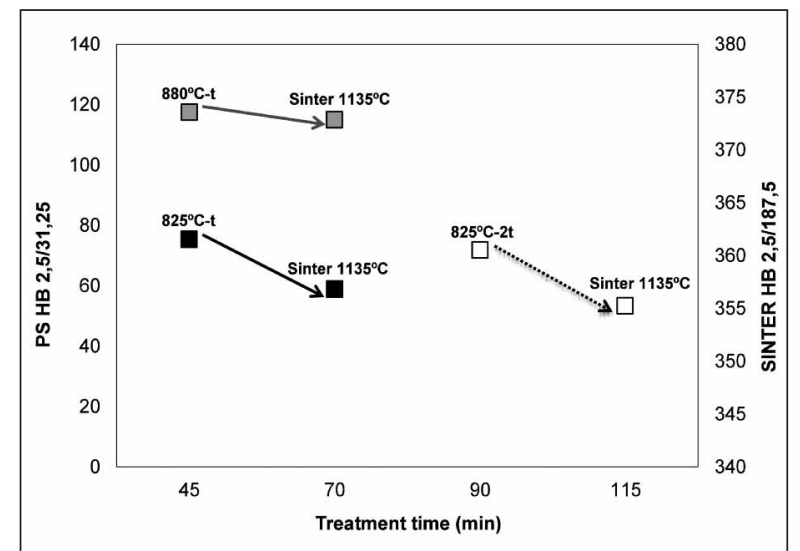

Ni4Cu2Mo1.5

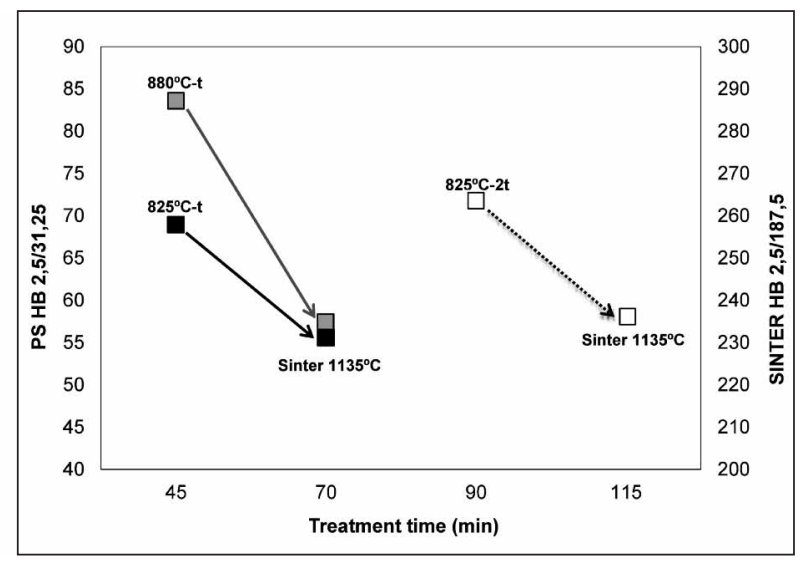

Ni4Cu1.5Mo0.5

Figure 7. Hardness values (Brinell), measured per trial.

Figura 7. Dureza (Brinell) de los materiales 1 y 2 por ciclo.

It is possible to confirm that, while significant difference in the hardness values in part after second sintering cannot be claimed when the presintering temperature is $880^{\circ} \mathrm{C}$, dimensions of the parts produced with $\mathrm{Ni4Cu} 2 \mathrm{Mo} 1.5$ vary significantly.

In figures 8 and 9 , the values of the applied load and the elongation of the parts before breaking can be seen, as determined by the test described in figure 3 .

The best results for the applied load are obtained, as expected, for the most-alloyed material (Ni4Cu2Mo1.5). The pre-sintering conditions do not have a significant influence on the performance of this material. Ni4Cu1.5Mo0.5 shows a slight improvement of the measured values with both presintering parameters: time and temperature.
The larger values for the elongation are those obtained for $\mathrm{Ni} 4 \mathrm{Cu} 1.5 \mathrm{Mo0} .5$, which is in accordance with the hardness values.

Nevertheless, when the temperature is kept constant and the time is increased, the elongation of both materials presents a slight improvement. The increase in the elongation with time and temperature is strongly related to the density. Therefore, it can be concluded that the combined results related to the mechanical properties are better for Ni4Cu2Mo1.5 than for Ni4Cu1.5Mo0.5.

\subsection{Microstructure}

In figure 10, we can analyze the microstructure of the materials after the first press and sintering operation.

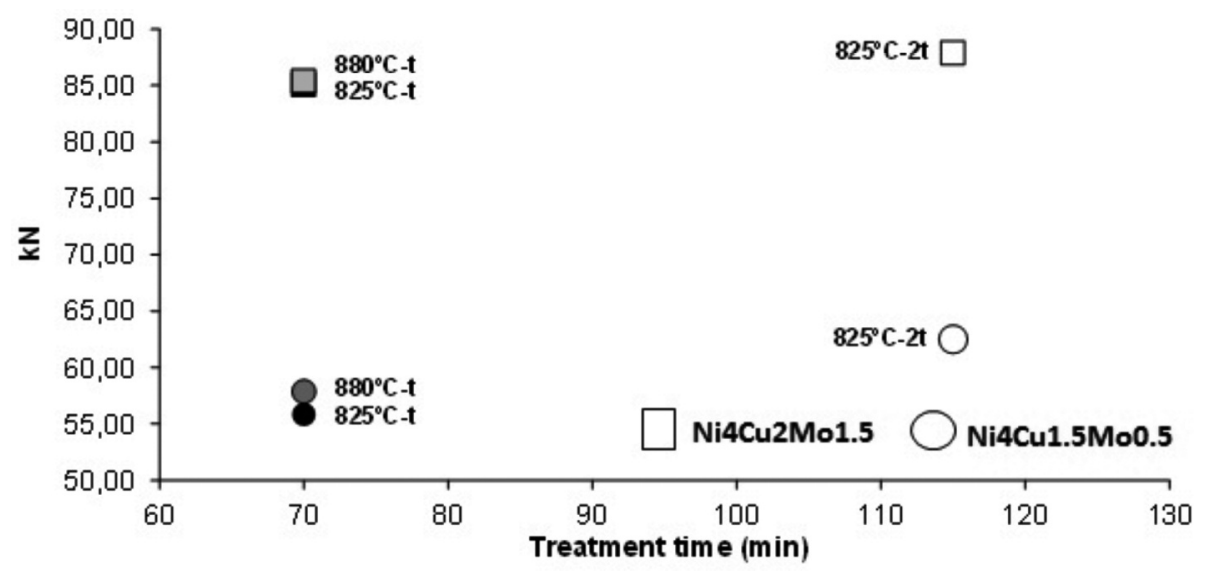

Figure 8. "In-house" breaking load test, after sintering.

Figura 8. Ensayos de rotura "in house." 


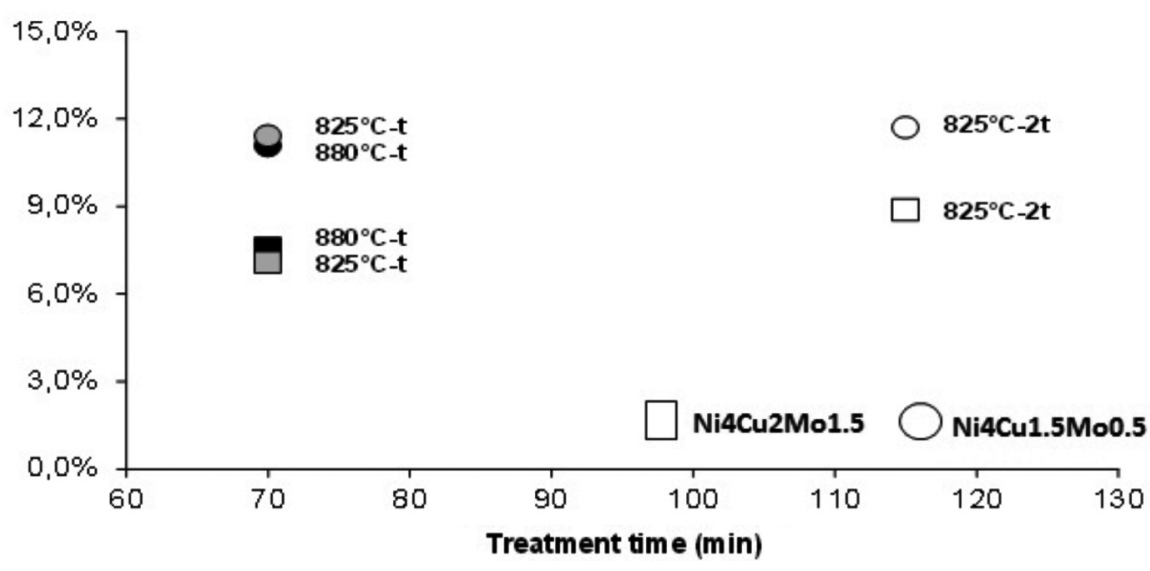

Figure 9. "In-house" breaking load test: "elongation".

Figura 9. Alargamiento en los ensayos de rotura "in house".

$825^{\circ} \mathrm{C}-\mathrm{t}$
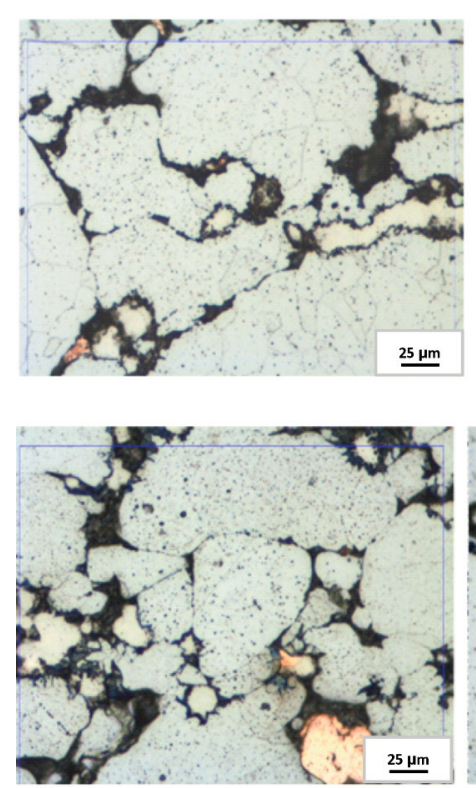

$825^{\circ} \mathrm{C}-2 \mathrm{t}$

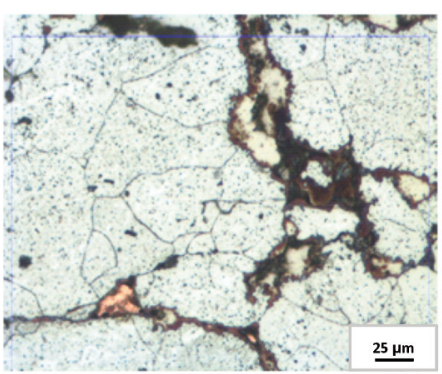

$880^{\circ} \mathrm{C}-\mathrm{t}$

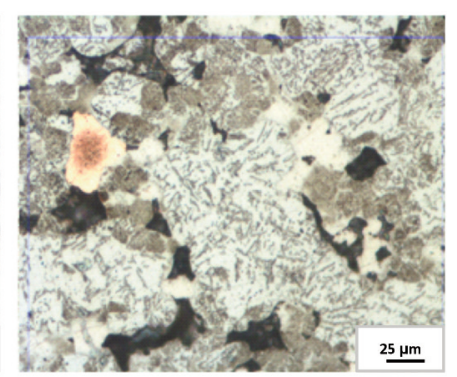

After 1P1S

$\mathrm{Ni4Cu} 2 \mathrm{Mo} 1.5$
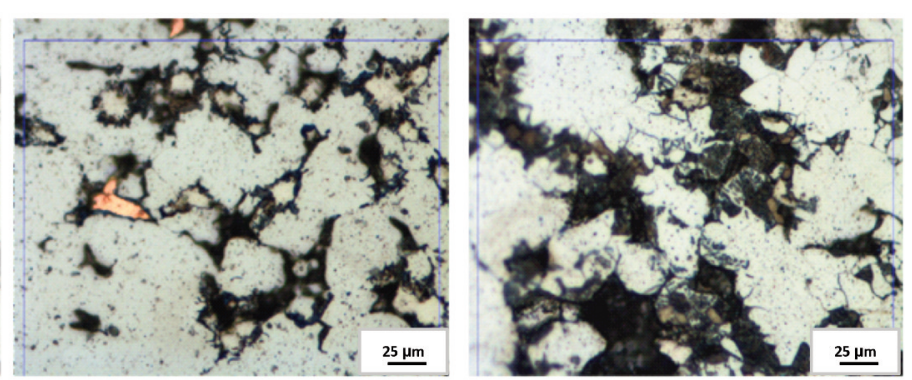

$\mathrm{Ni} 4 \mathrm{Cu} 1.5 \mathrm{Mo} 0.5$

Figure 10. Microstructures of the materials after the first press and sintering cycle.

Figura 10. Microestructuras de los materiales después del primer ciclo de prensado/sinterización.

In both materials, there is no diffusion of carbon at $825^{\circ} \mathrm{C}$, and the number of sintering necks increases when the sintering time is increased. For $\mathrm{Ni} 4 \mathrm{Cu} 2 \mathrm{Mo} 1.5$ at $880^{\circ} \mathrm{C}$, there is good diffusion of carbon inside the particles, and pearlite and bainite formation happen. These phenomena occur because molybdenum is fully pre-alloyed in this material, while in Ni4Cu1.5Mo0.5 it is diffusion bonded; additionally, the percentage of this element is larger, accounting for the difference in microstructure between the materials. It could be said that, for $\mathrm{Ni} 4 \mathrm{Cu} 2 \mathrm{Mo} 1.5$, when the presintering temperature is $880^{\circ} \mathrm{C}$, the proper sintering phenomenon has begun. These ideas are supported by the dimensional behavior of parts made of $\mathrm{Ni} 4 \mathrm{Cu} 2 \mathrm{Mo} 1.5$ after pre-sintering at $880^{\circ} \mathrm{C}$ : swelling exists, as it does after the proper sintering process.

In the case of Ni4Cu1.5Mo0.5, only a few pearlite grains are formed near the border of the former iron particles. Nickel-rich areas can also be identified in both materials, as they retain austenite.

In figure 11, the final microstructure of both materials can be seen.

The final microstructure for each material is quite similar for all of the processing routes, and in 
$825^{\circ} \mathrm{C}-\mathrm{t}$
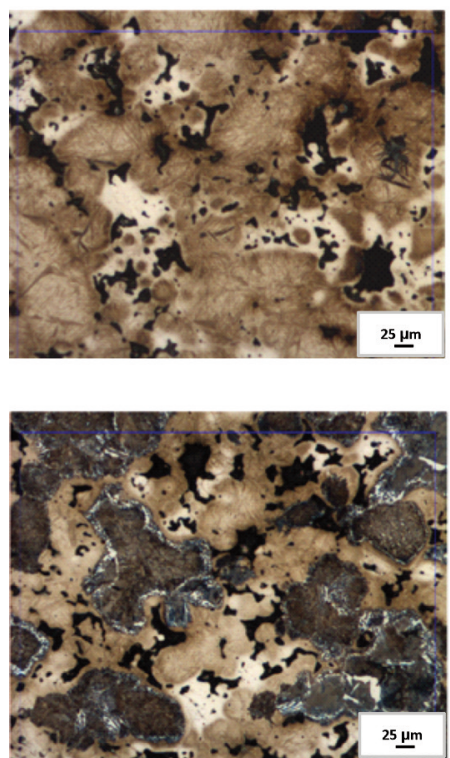

$825^{\circ} \mathrm{C}-2 \mathrm{t}$
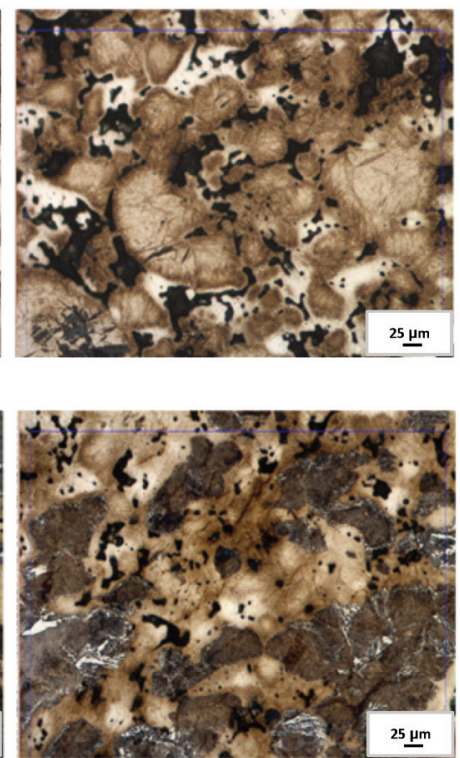

$880^{\circ} \mathrm{C}-\mathrm{t}$

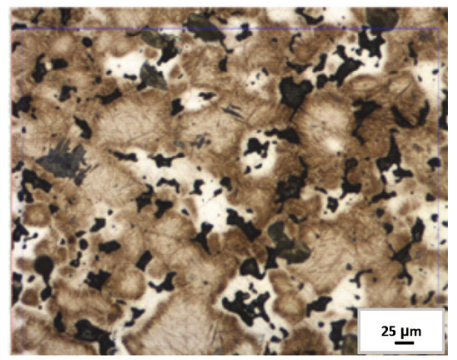

$\mathrm{Ni4Cu} 2 \mathrm{Mo} 1.5$

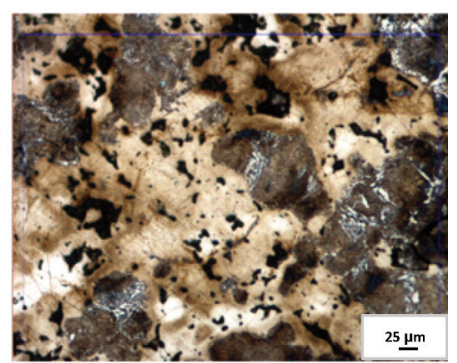

After 2P2S

Ni4Cu1.5Mo0.5

Figure 11. Microstructures of the materials in their final state, after the second press and sintering cycle.

Figura 11. Microestructuras de los materiales al final de los dos ciclos de prensado y sinterización.

accordance with the expected result for these materials. Ni4Cu2Mo1.5 consists mostly of lower

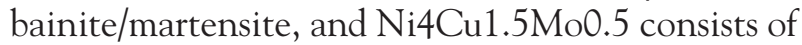
fine pearlite and lower bainite/martensite. This result is in agreement with those obtained when hardness, breaking load and elongation were measured.

Because nickel is diffusion bonded in both materials, nickel-rich areas present similar aspect. Differences between these areas have not been observed to depend on the pre-sintering conditions.

Engstrom ${ }^{[21]}$ compare these two materials using a standard test for tensile strength, and the results for the hardness, ultimate tensile strength and elongation are in full agreement with the results obtained here. These materials can exhibit robust performance improvements after heat treatments and high-temperature sintering.

\section{CONCLUSIONS}

The results of this work can be summarized as follows:

- The pre-sintering temperature defines the dimension after this stage (pre-sintering), but also after sintering for both materials. This effect is more pronounced in Ni4Cu2Mo1.5. In both materials, we can consider that the dimensional stability is acceptable for industrial applications. The effect of the pre-sintering temperature must be taken into account in tooling design.
- The hardness values after pre-sintering for Ni4Cu2Mo1.5 are increased with high presintering temperature. After sintering, this process route results in a slightly increased hardness, but no significant change. Ni4Cu1.5Mo0.5 does not present any significant hardness variation, either in the pre-sintering or sintering stage.

- The mechanical properties (breaking load) of the material are slightly improved with time and temperature. The improvement in Ni4Cu1.5Mo0.5 is more significant.

- The elongation of both materials is increased when pre-sintering time is doubled.

- The pre-sintering temperature has great influence on the pressing parameters, so any change in the pre-sintering conditions must be controlled to avoid further damage to the production equipment.

- After pre-sintering at high temperature, the material has started the sintering process (particularly Ni4Cu2Mo1.5), therefore, at this point second pressing operation for Ni4Cu2Mo1.5 is more similar to sizing than to traditional repressing operation. Due to this fact, an additional investigation via is open: machining operations which in normal conditions must be done after sintering could be done at this stage. Machining before final sintering is always an important cost-saving measure for the production process. 
- The main conclusion of this paper is the following: depending on the pre-sintering temperature, the dimensions of parts after the full process are completely different, especially for $\mathrm{Ni} 4 \mathrm{Cu} 2 \mathrm{Mo} 1.5$, keeping constant or slightly improving all other relevant characteristics, such as hardness and elongation. This result is relevant when considering the tolerance requirements for synchronizing hubs.

\section{REFERENCES}

[1] D. Whittaker, Metal Powder Report 50 (1995) 14-24.

[2] P. K. Johnson, Int. J. Powder Metall. 26 (1990) 57-61.

[3] P. Lindskog, Powder Metall. 47 (2004) 6-9.

[4] H. Danninger, Mater. Sci. Forum 426 (2003) $115-122$.

[5] J.M. Torralba, R. Oro and M. Campos, Mater. Sci. Forum 672 (2011) 3-11.

[6] J. Tengzelius, U. Engstrom, "Means to improve the dimensional tolerances of steel components", in "Modern Development in Powder Metallurgy", Ed. Metal. Powder Industries Federation, Princeton, EE.UU., 1985, pp. 743. 765.

[7] P. Lindskog, Powder Metall. 13 (1970) 280-294.

[8] G. Wastenson, Powder Metall. 18 (1975) 124-149.

[9] P. Lindskog, Materiaux et Techniques 64 (1975) 66-95.

[10] P.G. Arbstedt,, "Alloy Systems Developed for Pressing and Sintering in the Ferrous Field", in Alloy Composition and Microstructure Control in Relation to Processing, Ed. Metals Society, London, 1975, p. 37.

[11] P. Lindskog and O. Thornblad, Powder Metal. Int. 11 (1979) 10-11.

[12] W.C. Zapata, J.M. Torralba and J.M. Ruiz. "Comparative study of Cu-Ni-Mo sintered steels obtained from elemental mix and prealloyed powders", in "Horizons of Powder Metallurgy", Part II. European Powder Metallurgy Federation, 1986, pp. 1053-1056.

[13] J.M. Ruiz, J.M. Torralba, J.L. Sánchez, C. Ranninger and W.C. Zapata, "Influence of Molybdenum on properties and microestructure of sintered alloyed steels", in "Sintering'87", Ed. Elsevier Applied Science, 1, 1988, pp. 677-682.

[14] J. Tengzelius, Rev Metall-Paris 85 (1988) 1007 1013.

[15] K.L. Narasimhan and J. Tengzelius, "P/M Low Alloy Steels-Alloying Methods and Continuous Improvement", in "Advances in Powder Metallurgy \& Particulate Materials”. Ed. Metal Powder Industries Federation, Princeton, EE.UU., 1992, pp. 153-172.

[16] C.M. Sonsino, J. Tengzelius, V. Arnhold, K. Lipp, R. Wahling and E. Hoffmann, in "Advances in Powder Metallurgy \& Particulate Materials." Ed. Metal Powder Industries Federation, Princeton, EE.UU., 1992, pp. 115 125.

[17] F. Chagnon and M. Gagné, "Machining sinter hardenable P/M materials" Proceedings of the 1998 World Congress on Powder Metallurgy, Granada, Spain, 1998, pp. 384-389.

[18] J. Tengzelius, "Advances in Steel Powders for High Performance PM Parts", Proceeding of the Powder Metallurgy Conference, PMAsia 2005 Shanghai, 2005.

[19] M. Campos, L. Blanco, J. Sicre-Artalejo and J.M. Torralba, Rev. Metal. Madrid, 44 (2008) 5-12.

[20] B. Lindsley and T. Murphy, Mater. Sci. Forum, 534-536 (2007) 665-668.

[21] U. Engstrom, "Influence of sintering temperature on properties of low alloyed high strength PM materials", in "Advances in Powder Metallurgy \& Particulate Materials”, Ed. Metal Powder Industries Federation, Princeton, EE.UU., 2001, pp. 204-215. 